\title{
Analysis of Reinforced Concrete Structure Considering the Influence of Soil Structure Interaction \\ ${ }^{* 1}$ Varsha R. Harne, ${ }^{2}$ N. S. Agrawal \\ ${ }^{1,2}$ Shri Ramdeobaba College of Engineering and Management, Nagpur-13, Maharashtra, India Email: harnevr@rknec.edu, agrawalns9@rknec.edu
}

Received: 22nd October 2019, Accepted: 31st January 2020, Published: 29th February 2020

\begin{abstract}
The response of the soil influences the motion of the structure and response of the structure changes the ground motion history making the competition very complex and this phenomenon is known as Soil Structure Interaction. Various field tests indicate that the Soil-Structure Interaction (SSI) has a very significant impact on behaviour of structural elements of multi-storeyed buildings, which may lead to an unexpected structural seismic responses and/or failure. In this study, a simple five storied structure with fixed support is modelled by using ETAB. Numerical results obtained from analysis of fixed-base condition are compared with the results obtained from flexible-base condition. It was observed that the flexibility of structure reduces the overall stiffness and at the same time the natural period of the system were increases with considering the influence of the Soil Structure interaction of the system. The presence of the soil in the structural analysis provides the result of various parameters such as storey displacement, storey drift which are nearer to the actual dynamic behaviour of the structure than those provided by the analysis of a fixed base structure.
\end{abstract}

Keywords

Soil Structure Interaction, Natural Time Period, Stiffness, Fixed Base, RCC Structure

\section{Introduction}

The response of the soil influences the motion of the structure and response of the structure changes the ground motion history making the competition very complex and this phenomenon is known as Soil Structure Interaction. [10] The dynamic behaviour of the structure with the impact of soil structure interaction is reflected is an increase in the shaking period in comparison with the fixed base model, which does not consider the supporting soil.[5] Due to the relative movement of soil medium affect the building to deform for some extent. This decreases the overall stiffness of structural system and these increases the natural period.[1] For low rise building constructed on soft soil the effects of SSI become higher when subjected to earthquake load. Ramadan (2012) [8] investigated that increases the construction cost due to neglecting effect of seismic response analysis in soil structure interaction. Hence the analysis of Soil-Structure Interaction of high rise buildings [7] is the main focus of this research. In this work emphasis is laid to analyse a five story building for the influence of soil structure interaction on the structure. Modelling of the building is carried out for fixed-base as well as for flexible-base condition [9] using ETABs.

The main objectives of the study are;

i) To estimate the effects of Soil Structure Interaction (SSI) by using dynamic properties of structure rest on medium stiff soil

ii) To compare the result of fixed base with flexible base condition obtained for building from the ETABs

iii) To compare the results for different parameters such as the lateral displacement, natural frequency, story

drifts and time period with respect of no. of storey of building

\section{Materials and Methods}

\section{Mathematical Modelling}

For the analysis, a six storey RCC building is considered. The plan of building is symmetrical about X-axis and $\mathrm{Y}$-axis as shown in fig. 1 . It has 5 bays of $4 \mathrm{~m}$ width in $\mathrm{X}$ - direction and 5 bays of $3 \mathrm{~m}$ width in $\mathrm{Y}$ direction. Height of each floor is $3 \mathrm{~m}$ and $1.5 \mathrm{~m}$ below the ground level.

\section{Soil Conditions}

Foundation is considered to be resting on Medium hard soil. Different parameters such as Shear wave velocity (Vs), Poisson's Ratio $(\mu)$, Density of soil $(\rho)$ and shear modulus $(G)$ for different types of soil are required for analysis and this is considered from IBC CODE-2006. [5] The shear modulus (G) is estimated from the following expression $\mathrm{G}=(\mathrm{Vs})^{2} * \rho[10]$

Details of soil properties and material properties are considered as per table 1 and table 2 


\begin{tabular}{|l|c|c|c|}
\hline \multicolumn{1}{|c|}{ Types of Soil } & $\begin{array}{c}\text { Shear wave velocity }(\mathbf{V s}) \\
(\mathbf{m} / \mathbf{s e c})\end{array}$ & Poisson's ratio $(\boldsymbol{\mu})$ & Density of soil $(\boldsymbol{\rho}) \mathbf{( k N / \mathbf { m } ^ { 3 } )}$ \\
\hline Stiff soil & 750 & 0.3 & 18 \\
\hline Medium Stiff soil & 360 & 0.4 & 16 \\
\hline Soft soil & 180 & 0.4 & 16 \\
\hline
\end{tabular}

Table 1: Details of Soil Parameters

III. Material Properties

\begin{tabular}{|l|l|c|}
\hline \multicolumn{1}{|c|}{ Component } & \multicolumn{1}{|c|}{ Description of Model } & Data \\
\hline \multirow{5}{*}{ Model details } & Number of storey & 6 \\
\cline { 2 - 3 } & Number of bays in x direction & 5 \\
\cline { 2 - 3 } & Number of bays in y direction & 5 \\
\cline { 2 - 3 } & Floor height & 3000mm except bottom story 1500mm \\
\cline { 2 - 3 } & Bay width in X direction & $4000 \mathrm{~mm}$ \\
\cline { 2 - 3 } & Bay width in Y direction & $3000 \mathrm{~mm}$ \\
\cline { 2 - 3 } & Size of beam & $230 \times 400 \mathrm{~mm}$ \\
\cline { 2 - 3 } & Size of column & $300 \times 600 \mathrm{~mm}$ \\
\cline { 2 - 3 } & Thickness of slab & $150 \mathrm{~mm}$ \\
\cline { 2 - 3 } & Grade of concrete & M 25 \\
\cline { 2 - 3 } & Grade of steel & Fe500 (HYSD) \\
\hline Soil & Type of soil & Medium stiff soil \\
\cline { 2 - 3 } & Type of footing & Isolated footing \\
\hline Seismic parameters [1] & Type of structure & SMRF \\
\cline { 2 - 3 } & Seismic zone & V (severe) \\
\cline { 2 - 3 } & Importance factor (I) & 5 \\
\cline { 2 - 3 } & Response reduction factor (R) & 1 \\
\hline
\end{tabular}

Table 2: Geometric and Material Properties of Frame, Footing and Soil

\section{Spring Model Idealization}

The movement of the foundation is generally considered in three different directions out of that two are horizontal and one in vertical direction.[4] Therefore, the rotations of the building about these three directions are to be considered. Hence, from the accepted literatures of Gazetas 1991,[2] the building is modelled with isolated footing, three translational springs along three directions and three rotational springs about those mutually perpendicular axes should be put together below every column to estimate the effect of soil flexibility.[3]

Details of Spring Stiffness values are considered as per given below table 3.

\begin{tabular}{|c|c|}
\hline $\begin{array}{c}\text { Degree of Freedom } \\
\text { (Soil I for Exterior Column) }\end{array}$ & $\begin{array}{c}\text { Stiffness of Equivalent Soil Spring } \\
(\mathbf{k N} / \mathbf{m})\end{array}$ \\
\hline Vertical Direction & 22458760.49 \\
\hline Horizontal (Transverse Direction) & 27332188.79 \\
\hline Horizontal (Longitudinal direction) & 22103279.2 \\
\hline Rocking (Longitudinal Direction) & 39734787.35 \\
\hline Rocking (Transverse Direction) & 47666679.52 \\
\hline Torsion & 179468.8641 \\
\hline
\end{tabular}

Table 3 (a): Spring Stiffness Values (Soil I for Exterior Column)

\begin{tabular}{|c|c|}
\hline $\begin{array}{c}\text { Degree of Freedom } \\
\text { (Soil II for Interior Column) }\end{array}$ & $\begin{array}{c}\text { Stiffness of Equivalent Soil Spring } \\
\text { (kN/m) }\end{array}$ \\
\hline Vertical Direction & 25330563.46 \\
\hline Horizontal (Transverse Direction) & 30857042.09 \\
\hline Horizontal (Longitudinal Direction) & 24975089.17 \\
\hline Rocking(Longitudinal Direction) & 68440613.69 \\
\hline Rocking (Transverse Direction) & 58537070.07 \\
\hline Torsion & 285323.7434 \\
\hline
\end{tabular}

Table 3 (b): Spring Stiffness Values (Soil II for Interior Column) 
Figure. 1 shows Winkler model of $(\mathrm{G}+5)$ Structure where the fixed support is replaced by spring with desired stiffness values as shown in Table 3 (a) and Table 3 (b).
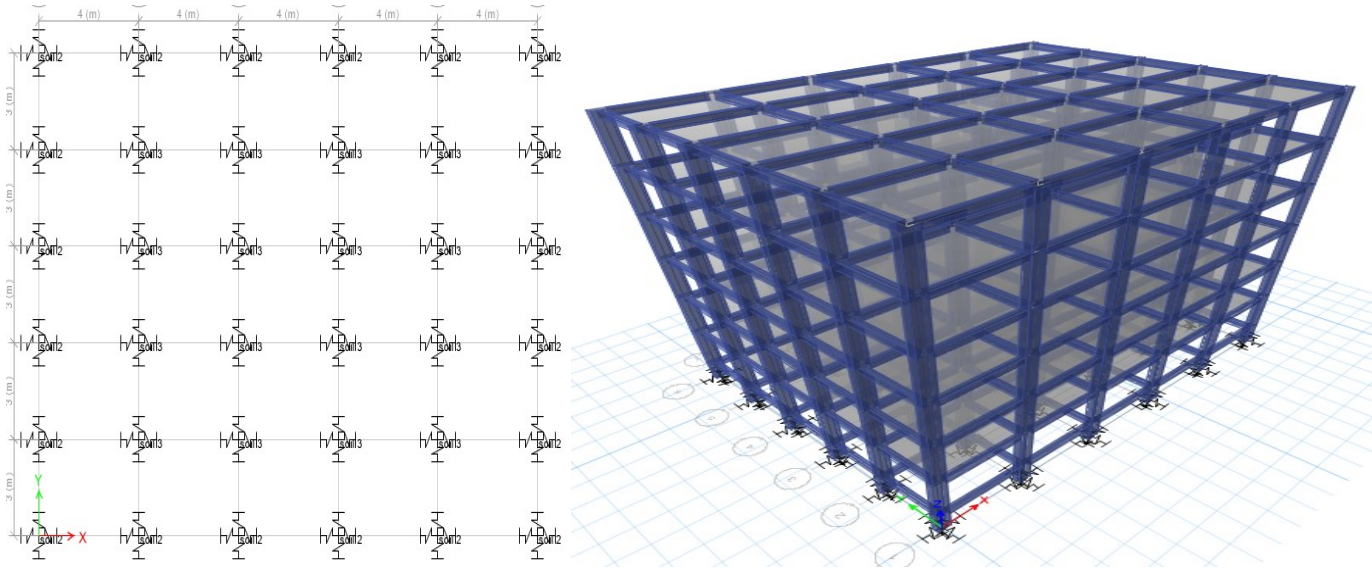

Figure 1: Winkler Model of $(G+5)$ Structure with Spring

\section{Results and Discussion}

A symmetric frame of 5 bays, 6 stories with isolated footing with corner footing size as $3.2 \mathrm{~m} \times 2.9 \mathrm{~m}$ and interior footing size as $3.6 \mathrm{~m} \times 3.3 \mathrm{~m}$ with soil structure model viz. Spring Winkler model is considered. The influence of with and without soil structure interaction is studied by considering the effect medium stiff soil and structural parameters based on seismic performance of building.[11]

The various parameters such as story stiffness, story drift, story displacement, fundamental modal period and frequencies are also studied and their comparisons are also studied.

\section{Story Stiffness}

\begin{tabular}{|c|c|c|}
\hline Story Height (m) & $\begin{array}{c}\text { Story Stiffness (kN/m) } \\
\text { Fixed Base }\end{array}$ & $\begin{array}{c}\text { Story Stiffness (kN/m) } \\
\text { Flexible Base }\end{array}$ \\
\hline 19.5 & 219282.43 & 219076.4 \\
\hline 16.5 & 263357.957 & 263194.7 \\
\hline 13.5 & 268056.611 & 267925 \\
\hline 10.5 & 271424.751 & 271302.5 \\
\hline 7.5 & 288437.267 & 288296.2 \\
\hline 4.5 & 377516.321 & 377217.4 \\
\hline 1.5 & 2180986.756 & 2173322 \\
\hline
\end{tabular}

Table 4: Tabulated Value of Story Stiffness $(\mathrm{kN} / \mathrm{m})$ for EQx

\begin{tabular}{|c|c|c|}
\hline Story Height (m) & $\begin{array}{c}\text { Story Stiffness (kN/m) } \\
\text { Flexible Base }\end{array}$ & $\begin{array}{c}\text { Story Stiffness (kN/m) } \\
\text { Fixed Base }\end{array}$ \\
\hline 19.5 & 199375.634 & 199727.962 \\
\hline 16.5 & 213492.321 & 213711.461 \\
\hline 13.5 & 214481.897 & 214653.716 \\
\hline 10.5 & 215144.163 & 215297.774 \\
\hline 7.5 & 217870.243 & 218020.565 \\
\hline 4.5 & 245081.004 & 245265.116 \\
\hline 1.5 & 1450838.223 & 1453753.013 \\
\hline
\end{tabular}

Table 5: Tabulated Value of Story Stiffness (kN/m) for EQy 
2. Storey Drift

\begin{tabular}{|c|c|c|}
\hline Story Height (m) & $\begin{array}{c}\text { Story Drift } \\
\text { Flexible Base }\end{array}$ & $\begin{array}{c}\text { Story Drift } \\
\text { Fixed Base }\end{array}$ \\
\hline 19.5 & 0.000913 & 0.000824 \\
\hline 16.5 & 0.001453 & 0.001083 \\
\hline 13.5 & 0.001827 & 0.001382 \\
\hline 10.5 & 0.001954 & 0.001555 \\
\hline 7.5 & 0.001955 & 0.001556 \\
\hline 4.5 & 0.001517 & 0.001225 \\
\hline 1.5 & 0.0005309 & 0.0004306 \\
\hline 0 & 0 & 0 \\
\hline
\end{tabular}

Table 6: Tabulated Value of Story Drift for 1.5 (DL -EQx)

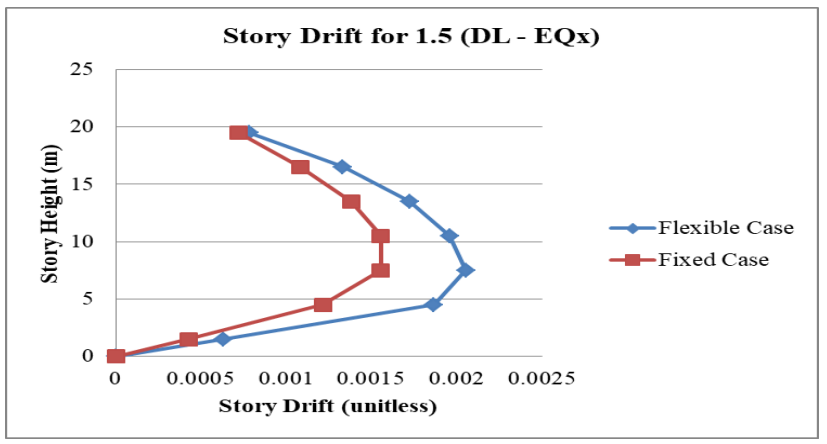

Fig 2: Maximum Story Displacement (X Direction) Pertaining to Story Height

\begin{tabular}{|c|c|c|}
\hline Story height (m) & $\begin{array}{c}\text { Story Drift } \\
\text { Flexible base }\end{array}$ & $\begin{array}{c}\text { Story Drift } \\
\text { Fixed base }\end{array}$ \\
\hline 19.5 & 0.000985 & 0.000788 \\
\hline 16.5 & 0.001666 & 0.001333 \\
\hline 13.5 & 0.002157 & 0.001725 \\
\hline 10.5 & 0.00245 & 0.00196 \\
\hline 7.5 & 0.002571 & 0.002057 \\
\hline 4.5 & 0.002335 & 0.001868 \\
\hline 1.5 & 0.000792 & 0.000633 \\
\hline 0 & 0 & 0 \\
\hline
\end{tabular}

Table 7: Tabulated Value of Story Drift for 1.5 (DL - EQy)

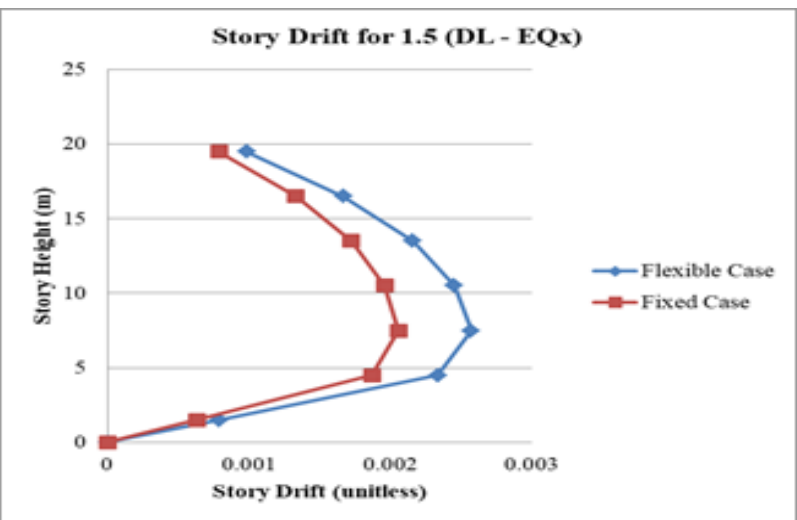

Fig 3: Maximum Story Displacement (Y direction) Pertaining to Story Height 
3. Story Displacement

\begin{tabular}{|c|c|c|}
\hline Story Height (m) & $\begin{array}{c}\text { Story Displacement (mm) } \\
\text { Flexible Base }\end{array}$ & $\begin{array}{c}\text { Story Displacement (mm) } \\
\text { Fixed Base }\end{array}$ \\
\hline 19.5 & 29.2 & 23.1 \\
\hline 16.5 & 26.1 & 21.2 \\
\hline 13.5 & 22.1 & 17.5 \\
\hline 10.5 & 17.2 & 13.4 \\
\hline 7.5 & 11.1 & 8.89 \\
\hline 4.5 & 5.3 & 4.3 \\
\hline 1.5 & 0.8 & 0.6 \\
\hline 0 & 0.002345 & 0 \\
\hline
\end{tabular}

Table 8: Tabulated Value of Story Displacement for 1.5 (DL - EQx)

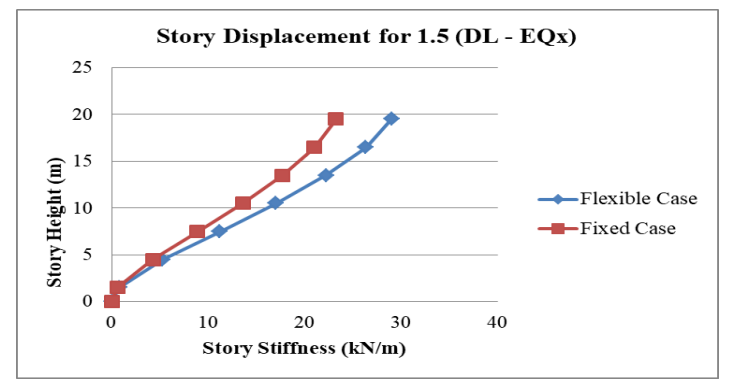

Fig 4: Graphical Representation of Max. Story Displacement (X Direction) Pertaining to Story Height

\begin{tabular}{|c|c|c|}
\hline Story Height (m) & $\begin{array}{c}\text { Story Displacement (mm) } \\
\text { Flexible Base }\end{array}$ & $\begin{array}{c}\text { Story Displacement (mm) } \\
\text { Fixed Base }\end{array}$ \\
\hline 19.5 & 36.7 & 30.1 \\
\hline 16.5 & 35.7 & 27.7 \\
\hline 13.5 & 29.7 & 23.7 \\
\hline 10.5 & 22.3 & 18.5 \\
\hline 7.5 & 15.9 & 12.7 \\
\hline 4.5 & 8.2 & 6.4 \\
\hline 1.5 & 1.3 & 1 \\
\hline 0 & 0.002031 & 0 \\
\hline
\end{tabular}

Table 9: Tabulated Value of Story Displacement for 1.5 (DL - EQy)

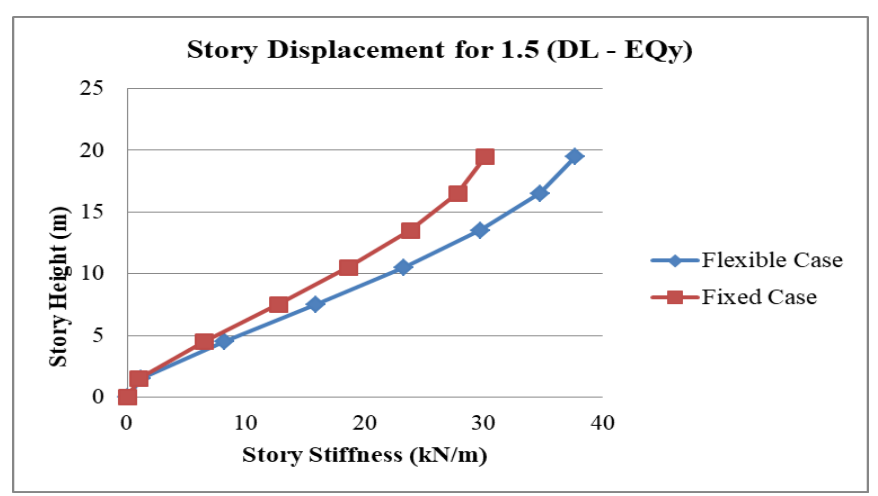

Fig 5: Graphical Representation of Max. Story Displacement (Y Direction) Pertaining to Story Height 


\begin{tabular}{|c|c|c|}
\hline Mode & $\begin{array}{c}\text { Period (Sec) } \\
\text { Fixed-Base }\end{array}$ & $\begin{array}{c}\text { Period (Sec) } \\
\text { Flexible-Base }\end{array}$ \\
\hline 1 & 0.796 & 0.808 \\
\hline 2 & 0.686 & 0.679 \\
\hline 3 & 0.673 & 0.681 \\
\hline 4 & 0.259 & 0.265 \\
\hline 5 & 0.214 & 0.1219 \\
\hline 6 & 0.209 & 0.212 \\
\hline 7 & 0.149 & 0.154 \\
\hline 8 & 0.118 & 0.123 \\
\hline 9 & 0.109 & 0.114 \\
\hline 10 & 0.103 & 0.107 \\
\hline 12 & 0.079 & 0.085 \\
\hline
\end{tabular}

Table 10: Tabulated Values of Fundamental Time Period

\begin{tabular}{|c|c|c|}
\hline \multirow{2}{*}{ Mode } & Period (Cycle/Sec) & Period (Cycle/Sec) \\
\cline { 2 - 3 } & Fixed Base & Fixed Base \\
\hline 1 & 1.703 & 1.669 \\
\hline 2 & 1.948 & 1.934 \\
\hline 3 & 2.115 & 2.074 \\
\hline 4 & 5.121 & 4.975 \\
\hline 5 & 6.028 & 5.617 \\
\hline 6 & 6.325 & 6.097 \\
\hline 7 & 8.202 & 7.575 \\
\hline 8 & 10.136 & 9.900 \\
\hline 9 & 10.29 & 9.615 \\
\hline 10 & 20.92 & 17.857 \\
\hline 11 & 22.042 & 19.230 \\
\hline 12 & 24.046 & 20.408 \\
\hline
\end{tabular}

Table 11: Tabulated Values of Fundamental Frequencies

Conclusion

As per analyses, the following conclusions are to be recommended.

1. Among all the load combination, the most critical load combination was found to be 1.5(DL- EQ) for both direction i.e $\mathrm{X}$ as well as $\mathrm{Y}$ - direction.

2. For this load combination the storey displacement values increases with increase in soil flexibility means displacement value for flexible base condition is more than fixed based condition.

3. Similarly for the story drift values increases with increase in soil flexibility.

4. Considering the effect of flexibility, it has reduces the overall stiffness of the structure. Therefore, optimized design should be adopted while construction of the structure so that the structure can desirably resist the earthquake effects acting on it.

5. As the height of the building increases, the lateral displacement, natural frequency, story drifts and time period increases.

6. It was also concluded that, if the fundamental natural period of the system is increase then the fundamental frequency of the system is decreases.

7. Base shear value for the structure with fixed-base condition and flexible-base condition has not varied; this is because the structure for both conditions is analyzed for only medium hard soil.

\section{References}

[1] Anuradha, Dr. H. M. Somasekharaiah, (2015) "Soil Structure Interaction Effect on the Dynamic behavior of irregular R. C. frame with isolated footings", IJSRD-International Journal for Scientific Research and Development| Vol.3, Issue 04, 2015.

[2] Gazetas, G. (1991), "Formulas and charts for impedances of surface and embedded foundations", Journal of Geotechnical Engineering., 117, 9: 1363-1381.

[3] G. Saad, F. Saddik, S. Najjar, "Impact of SSI on the seismic design of reinforced concrete buildings with underground stories", the 15 th World Conference on Earthquake Engineering (2012). 
[4] H. Matinmanesh and M. Saleh Asheghabadi, "seismic analysis on soil-structure interaction of buildings over sandy soil", The Twelfth East asia-Pacific Conference on structural engineering and Construction (2011).

[5] IBC - 2006, "International building code 2006

[6] Julio A. Garcia, "Soil Structure Interaction in the analysis and seismic design of reinforced concrete frame buildings", the 14th World Conference on Earthquake Engineering (2008).

[7] Mengke Li, xiao Lu, Xinzheng Lu, Lieping Ye, "Influence of soil-structure interaction on seismic collapse resistance of super-tall building”, Journal of Rock Mechanics and Geotechnical Engineering (2014).

[8] O.M.O. Ramadan, "Effects of soil structure interaction of nonlinear seismic response of building", the $15^{\text {th }}$ World Conference on Earthquake Engineering (2012).

[9] Rahul Sawant, Dr. M. N. Bajad, "Effect of Soil-Structure Interaction on High Rise RC Building", IOSR Journal of Mechanical and Civil Engineering (IOSR-JMCE), Volume 13, Issue 1 Ver. IV (janfeb.2016),PP 85-91.

[10] Shrabony Adhikary, Yogendra Singh and D. K. Paul, Department of Earthquake Engineering, IIT Roorkee, "Modelling of soil foundation structure system."

[11] Shehata E. Abdel Raheem, Mohamed M. Ahmed. Tarek M. A. Alazrak, "Evaluation of soilfoundation- stricture interaction effects on seismic response demands of multi story MRF buildings on raft foundations”, Int J Adv Struct Eng (2015) 7:11-30. 